\title{
Reis-Filósofos Na Busca Por Uma Sociedade Idealizada: análise socioeducacional do filme Capitão Fantástico
}

\section{Philosopher Kings In The Search For An Ideal Society:socio-educational analysis of the movie Captain Fantástico}

\author{
Altina Abadia da Silva ${ }^{1}$ \\ Danyelle Borges de Oliveira ${ }^{2}$ \\ Viviane Faria Lopes ${ }^{3}$
}

\begin{abstract}
RESUMO
Esta pesquisa tem como objetivo analisar as escolhas da família que figuram a produção cinematográfica Capitão Fantástico, lançada no ano de 2016, cujos membros vivem de modo não convencional, com os progenitores criando os filhos isolados da sociedade para, desse modo, torná-los efetivos reis-filósofos, com base no que é exposto em A República, de Platão. Buscando fugir da dominação política global, passaram a viver uma realidade autônoma, isentos de universos nos quais o autoritarismo perpassa, alicerçados na ideia de uma sociedade sublime, idealizada. Tal investigação buscou situações sociais e políticas atuais, recorrentes no Brasil, para firmar comparação, e balizou-se em teóricos da sociologia, da linguagem e da educação, para promover uma análise socioeducacional do conhecimento erudito enquanto componente necessário, apesar de não exclusivo para a formação de jovens pensadores e construtores de conhecimento.
\end{abstract}

Palavras-chave: Práticas sociais; Educação, Conhecimento.

\section{ABSTRACT}

This research aims to analyze the family choices that appear in the film production Captain Fantastic, launched in 2016, whose members live in an unconventional way,

\footnotetext{
${ }^{1}$ Doutora em Educação pela Universidade Metodista de Piracicaba. Professora no curso de Pedagogia e Programa de Pós-graduação em Educação - PPGEDUC da UFG/ Regional Catalão.

${ }^{2}$ Aluna do Programa de Pós-graduação em Educação (PPGEDUC) da Universidade federal de Goiás Catalão, GO. E-mail: danyelle_borges_@hotmail.com

${ }^{3}$ Doutora em Linguística pela Universidade de Brasília (UnB). Professora no curso de Letras - graduação e pós-graduação - da Universidade Estadual de Goiás (UEG). Pesquisadora do Núcleo de Estudos em Linguagem e Sociedade (Nelis) da UnB. Coordenadora do Grupo de Pesquisa em Saúde Mental na UEG. E-mail: viviane.lopes@ueg.br
} 
with the parents raising the isolated children of the society in order, in this way, to make them effective kings-philosophers, based on what is exposed in The Republic, of Plato. Seeking to escape global political domination, they began to live an autonomous reality, free from universes in which authoritarianism permeates, based on the idea of a sublime, idealized society. Such investigation sought current social and political situations, recurring in Brazil, to establish comparison, and was based on theorists of sociology, language and education, to promote a socio-educational analysis of erudite knowledge as a necessary component, although not exclusive for the training of young thinkers and knowledge builders.

Keywords: social practices, education, knowledge.

\section{INTRODUÇÃO}

Filósofo e matemático afamado, Platão ${ }^{4}$ foi pensador do período clássico da Grécia Antiga e, consequentemente, produziu diálogos especutalativos que balizam até hoje a chamada filosofia ocidental. Fundou, em Atenas, o que seria a primeira instituição de conhecimento e educação superior do mundo, nomeada de Academia (PAVIANI, 2001). Segundo os apontamentos de Paviani (2001), o filósofo em questão fora um jovem privilegiado de sua geração, o que o motivou a ambicionar a conquista de cargos políticos elevados. Todavia, a condenação de Sócrates ${ }^{5}$, a quem seguia como discípulo e tinha como referência de erudição, interferiu em sua visão política, bem como em sua maneira de avaliar a própria vida.

Ainda de acordo com os estudos filosóficos de Paviani (2001), essa tragédia levou Platão a reconsiderar o conceito e formato de democracia, fazendo-o acreditar que a verdadeira filosofia seria, portanto, capaz de iluminar os homens e os levar ao reconhecimento e à prática da justiça, quer seja na vida pública, quer seja na privada. Dessa elucubração a respeito dos alicerces sociais de sua época, Platão formulou o pensamento conceitual de que somente reis-filósofos seriam capazes de alcançar a plena

\footnotetext{
${ }^{4}$ Atenas, 428/427 a.C. - 348/347 a.C.

${ }^{5}$ Alópece, 469 a.C. - Atenas, 399 a.C.
} 
consciência do campo da razão superior. Para o ateniense, tais figuras de autoridade trariam, em sua caracterização, a busca apaixonada e contínua pela verdade, com a reflexão ajuizada levando-os ao acreditado mundo das ideias, que fornece o sublime conhecimento a seus buscantes e os conduz ao bem verdadeiro.

A produção cinematográfica Capitão Fantástico (2016) apresenta uma família não convencional, cujos progenitores criaram os filhos isolados da sociedade para, desse modo, torná-los efetivos reis-filósofos, com base no que é exposto em A República, de Platão. O intento dos pais foi, à luz de sua compreensão, firmarem a negação de valores colocados pela dominação política global e viverem de modo autônomo, isentos de universos nos quais o autoritarismo perpassa. A criação é pautada em aprendizado de sobrevivência na selva, tendo primordialmente os recursos naturais, até o conhecimento erudito de literatura, música, filosofia e leis, alicerçados na ideia de uma sociedade sublime, idealizada.

Em um pensamento crítico contemporâneo, Durkheim (2011) reflete criteriosamente a respeito das concepções criadas por pensadores diversos que razoam uma educação idealizada para um homem igualmente idealizado. Diante disso, o sociólogo coloca em relevância o uso de autores clássicos para balizar pensamentos que tratam das relações humanas contemporâneas, como, por exemplo, o fato social conceito esse elaborado pelo próprio Durkheim (2011, p. 55). Em seus estudos, ele aponta maneiras de agir, pensar e sentir que são exteriores ao indivíduo e, por isso, leva-o a ter que se adaptar, ainda que exija esforço para não ser afetado (DURKHEIM, 2001).

Colocar conceitos filosóficos em um mundo tão plural exige uma reelaboração crítica de percepções, as quais tendem a se desenvolver em modelos educacionais coerentes e adequados a cada realidade, pois relocar autores clássicos à contemporaneidade reclama contextualização social e cultural, a fim de que suas teorias sejam adequadamente utilizadas enquanto pensamento profícuo e de proveito cotidiano. Dessa forma, como seria reviver a ideia de Platão a respeito dos reis-filósofos, bem como de que modo, em quais fontes e em que aspectos seria possível o alcance do mundo das ideias? Em uma sociedade amplamente pautada em tecnologia, velocidade de informação e indução de pensamento consumidor, seria possível uma haver os amantes reflexivos da verdade? 


\section{"Eu tive o desejo de me dedicar exclusivamente à pesquisa da verdade"}

Para Descartes ${ }^{7}$, a busca pelo raciocínio verdadeiro pautava-se tanto na filosofia quanto nas ciências exatas, com um discernimento analítico a traçar o pensamento e o comportamento de modo a enlevá-los às verdadeiras necessidades humanas, diferentemente da vertente teocêntrica medieval, cuja doutrina considerava a crença imaterial como fundamento da ordem do mundo, sendo, portanto, de uma composição de senso crítico exíguo. Graças aos filósofos e cientistas dessa época, o conhecimento teve sua forma e função alteradas, de modo a criar moldes que contribuíssem para e emersão da sociedade que se reconstruía, com os pensadores formulando e concebendo ciência sem o controle e a retenção religiosa (RONAN, 1987).

No presente momento histórico, o Brasil tem sido alvo de uma tendência cartesiana que vem aumentando em seus últimos anos, na qual a racionalidade enérgica justifica ações extremistas que se distanciam da atividade sistemática de Descartes, cujo movimento intelectual formulado precipuamente enfatizava a aplicação da razão para o desenvolvimento das ciências naturais (DESCARTES, 2010). Em sua obra, Capra (2006) fala da tendência histórica da repetição cíclica, por exemplo, onde erros repulsam pelas mãos da humanidade e pensamentos obscuros, seguidos de reflexões libertadoras, retomam a mente coletiva.

O país vive, a exemplo dessa reincidência, uma crise do pensamento reflexivo, tendo o avanço popular a estar se deixando levar por ideologias obsoletas, com as crises sociopolíticas a fomentarem o pensamento anacrônico de modo a criar soluções plausíveis (POPULAÇÃO..., 2016). O desequilíbrio social é, por sua vez, um momento propício para a recriação de modelos, o que se pode chamar, ainda, de ponto de mutação. Capra coloca que "O termo que eles [chineses] usam para 'crise', wei-ji, é composto dos caracteres 'perigo' e 'oportunidade"” (CAPRA, 2006, p. 16). Sendo assim, é possível

\footnotetext{
6 DESCARTES, 2010.

7 Touraine, 1596 - Estocolmo, 1650.
} 
compreender que, ao se falar de recessão - seja do pensamento, da economia ou da filosofia - fala-se, também, da possível abertura de oportunidades de evolução, a depender da forma de enfrentamento por parte dos sujeitos que as arrostam.

O conhecimento formulado pelos autores clássicos, a compreensão crítica da história da humanidade e a análise do comportamento dos antepassados diante dos conflitos vividos apresenta uma significativa contextualização referencial que se faz imprescindível para a não repetição de atrocidades comportamentais, justificadas por resguardos à valores avaliados como importantes para o alicerce social. Ainda que tais motivações conservadoras tenham por pretexto a modernização, na verdade, fundamentam-se em influências manipuladoras de preceitos de fé, em que pessoas se permitem ser guiar por “crenças imateriais - não confirmadas pela ciência e nem legitimadas por experimentos -, envolvidas por ideologias nas quais concebem suas identidades e direcionam todo o seu modo de viver, o qual ainda pode incluir, infelizmente, atos atrozes de intolerância e destruição" (LOPES, 2019, p. 22).

Apesar de a ascensão do conservadorismo se apresentar como uma tendência mundial (POPULAÇÃO..., 2016), alguns lugares, como o Brasil, apontam uma direita política com tendências econômicas liberais. As ações de lucro norteiam-se do modo a visar a retornos imediatistas e, com isso, ignoram as sequelas advindas a médio e longo prazos.

Combinada com o modelo mecanicista do universo, que também se originou no século XVII, e com a excessiva ênfase dada ao pensamento linear, essa atitude produziu uma tecnologia que é malsã e inumana; uma tecnologia em que o habitat natural, orgânico, de seres humanos complexos é substituído por um meio ambiente simplificado, sintético e pré-fabricado.

Essa tecnologia tem por meta o controle, a produção em massa e a padronização, e está sujeita, a maior parte do tempo, a uma administração centralizada que busca a ilusão de um crescimento ilimitado. (CAPRA, 2006, p. 34)

De acordo com os apontamentos de Capra (2006), para que aconteça uma evolução é fundamental que haja, também, contradições. Senso assim, o pesquisador questiona a tecnologia como objeto de controle, como instrumento de limitação e, ainda, criador de fabulações de persuasão. 
Diante desse questionamento, faz-se oportuno tomar, para conjectura especulativa, a recente decisão governamental quanto ao Exame Nacional do Ensino Médio (ENEM). Segundo o Instituto Nacional de Estudos e Pesquisas Educacionais Anísio Teixeira (INEP), haverá mudança na realização do ENEM, prevista para 2020, com a aplicação a ser feita de modo digital, a qual está justificada na redução de custos (EXAME..., 2019). A notícia, publicada na própria página da corporação pública, explica que a aplicação será executada, no primeiro ano, em formato piloto, tendo sua implantação digital em proposta progressiva, de modo a ser consolidada em 2026 (EXAME..., 2019). Todavia, tendo em vista que "a significação não reside apenas no âmbito do linguístico, mas também na maneira como a usamos em contexto" (VIEIRA; SILVESTRE, 2015, p. 7), o que aparenta ser um avanço educacional deveria, na verdade, ser ponderado cuidadosamente por profissionais do ensino, já que não se trata, unicamente, de um formato avaliativo, afinal, interferirá no modo como o conhecimento será cobrado e, ainda, nos diversos letramentos exigidos desses jovens candidatos.

Outra situação a denotar a tendência conservadora regressista, de modo a fazer decair conquistas já firmadas após alta diligência de conscientização popular, está no retorno às discussões a respeito da abordagem da homossexualidade enquanto transtorno passível a tratamento. Em 17 de maio de 1990, a Organização Mundial de Saúde (OMS) considerou que homossexualidade não configura doença e, por isso, retirou-a da Classificação Internacional de Doenças (CONSELHO NACIONAL DOS DIREITOS HUMANOS, 2017), o que beneficiou as resoluções que apontam a homofobia como crime. Todavia, a revinda ao assunto, reclassificando-o enquanto possível desarranjo comportamental, permitiu ao Conselho Nacional dos Direitos Humanos a publicação de uma nota, diante do movimento de diversos psicólogos que quiseram oferecer a terapia de reorientação sexual, tendo, por justificativa, que o tal tratamento seria voltado somente ao sujeito que o quisesse, por se sentir em sofrimento psicológico por conta de sua sexualidade (Ação Popular $n^{\circ}$ 1011189-79.2017.4.01.3400). Diante disso, evidencia-se que a luta para proteger direitos e criminalizar a violência gerada por preconceitos seja, também, um esforço contínuo, visto que o Brasil é o país que mais mata homossexuais (NUNES, 2018) e, portanto, releva-se em seu crescente conservadorismo.

As questões sociais acima apontadas - uma de estrutura educacional e a outra de ideologia sociológica - exemplificam a tradição reacionária que se movimenta, em crescente força e conquista, no Brasil e no mundo. Essas afluências afetam a maneira com 
a qual será formada a identidade dos jovens, que se constroem balizados na formação social que lhes é oferecida pelos sistemas educacionais e pelos diversos meios comunicativos - os quais vêm se desenvolvendo em quantidade e diversidade, como, por exemplo, as redes sociais (VIEIRA; SILVESTRE, 2015).

O atual presidente da república, que utiliza redes sociais para fazer anúncios, afirmou o seguinte no Twitter $^{8}$ :

O Ministro da Educação @abrahamWeinT estuda descentralizar investimento em faculdades de filosofia e sociologia (humanas). Alunos já matriculados não serão afetados.

O objetivo é focar em áreas que gerem retorno imediato ao contribuinte, como: veterinária, engenharia e medicina. (fonte: https://twitter.com/jairbolsonaro/status/1121713997156425729 em 26/04/2019).

O pronunciamento público acima, feito pela maior autoridade nacional, traz, no mínimo, dois importantes quesitos para análise. Um deles, a ascensão das redes sociais enquanto forma intercursiva de valor e reconhecimento, defendida por Poster (2000) enquanto sistemas comunicativos eletrônicos que se apresentam como linguagens a determinar a vida social coletiva, em seus eventos sociais, econômicos, políticos e culturais (POSTER, 2000). Segundo Kress e Van Leeeuwen (2006), essa linguagem híbrida, feitada por combinações de palavras, imagens, cores, sons e movimentos, abarca mobilidade e apresentação semiótica múltipla, que, por isso, apresenta uma linguagem multimodal e de firmação dominante. Com isso, cria-se a necessidade de que os indivíduos, enquanto agentes sociais, incorporem "maior poder de discernimento a respeito do mundo multimodal, manifesto principalmente pelos gêneros multimodais, veiculados pelos meios midiáticos circundantes", e venham a compreender que os modos semióticos representam a verdade da afluência real, reconstruindo a realidade com imagens, além de perceberem de que forma "elas recortam o mundo e como intencionalmente podem omitir detalhes" (VIEIRA; SILVESTRE, 2015, pp. 44-45).

O segundo quesito a ser escrutinado está na consideração feita quanto à retirada de investimento em faculdades de humanas, tendo por alvos principais a Filosofia

${ }^{8}$ Rede social lançada em 2006 e que permite aos usuários a troca de mensagens diversas entre si, por meio do Website. 
e a Sociologia. Em sua força hegemônica, os dirigentes nacionais intentam submeter uma nova realidade à população, impondo, na retirada ou acréscimo de linhas de construção de conhecimento, uma readaptação a forças maiores, que sustentam autoridade social, científica e acadêmica, o que obriga à aceitação de concordância a novos valores. De acordo com Lopes e Silva (2019, p. 97), a maior "parte do conhecimento empírico humanamente aprimorado está representado em suas relações, as quais trazem o contexto a manifestar os aspectos construtores de sua composição linguístico-social”. Por isso, subtrair do sujeito o direito à reflexão, à criação de um senso crítico por meio da busca cogitativa do passado e dos elementos formadores do pensamento, torna-o um indivíduo isento de opiniões críticas e, portanto, facilmente manipulável. Afinal, conforme aponta La Boétie (2009, p. 38), os verdadeiros pensadores "são dotados de claro entendimento e espírito clarividente; não se limitam, como o vulgo, a olhar só para o têm adiante dos pés, olham também para trás e para frente e, estudando bem as coisas passadas, conhecem melhor o futuro e o presente", e, portanto, incomodam por sua posição transgressora, firmada e aperfeiçoada pelo estudo e pelo saber (LA BOÉTIE, 2009).

Fatos sociais são descritos como ações coercitivas que se impõe ao sujeito, sendo inerentes ao tempo presente (DURKHEIM, p. 55, 2011), e igualmente responsáveis por gerar sentimento de pertença aos grupos em que se está inserido - seja família, trabalho, escola, vizinhança, igreja, entre outros. Se o indivíduo não se adequa a determinados padrões de comportamento que são esperados dentro de determinada categoria, fica propenso à marginalização. É verdadeira, ainda, que sociedades que se mantém fechadas, como os amish ${ }^{9}$, por exemplo, são pautadas pelo determinismo e se mantêm estáveis durante períodos prolongados, já que não permitem abertura para o mundo exterior.

Portanto, os reversos sociais colocados anteriormente evocam a necessidade de um pensar aprofundado e fortalecido, a fim de que sejam avaliados adequadamente em sua apresentação e possíveis consequências. Encontra-se, em cada momento histórico, grupos que se reuniram na intenção de criar resistência aos preceitos verticalmente

${ }^{9}$ Os amish são uma comunidade religiosa estabelecida nos EUA e Canadá nos séculos XVIII e XIX, endogâmicos e autossuficientes. (Miguel Angel Criado, 04/08/2016: $<$ brasil.elpais.com> acesso em 13/05/2019). 
estabelecidos, usando o conhecimento adquiro e a educação como propulsores de confronto, não aceitando o domínio acrítico da massa como desculpa de desenvolvimento e promoção de bem-estar. Seria o formato trazido pela família de Capitão Fantástico (2016) a melhor forma de resposta e de enfrentamento às determinações injungidas pelo governo federal? Avaliemos.

\section{“O que criamos aqui pode ser único na existência humana"10}

Os alicerces filosóficos propostos por Platão foram fundamentais para considerar o papel da educação na formação dos sujeitos. Com sustentáculos dialéticos, a forma de instrução platônica não era tratada com o objetivo de fazer seus seguidores, unicamente, alçarem patamares superiores, mas, antes, de promover a adequação a um papel a ser desempenhado socialmente.

A narrativa do filme Capitão Fantástico coloca os pais - Bem e Leslie - a vangloriarem-se de haver alcançado os ideais de educação propostos em A República. Fornecendo aos filhos um conjunto aprofundado e elevado de instrução clássica, abarcando as diversas áreas de conhecimento, o casal os leva à reflexão acentuada, bem como a um senso crítico proeminente e evidentemente superior ao comum. Distante da população que está tomada pelo sistema persuasivo, opressor e limitante, a família vive em harmonia com a natureza, obtém dela sua forma de sobrevivência e discute fundamentos culturais, históricos e científicos com uma destreza excelsa. Isentos de utensílios e dispositivos tecnológicos, dedicam-se ao aprimoramento físico e intelectual, além da dedicação ao aprendizado de instrumentos musicais e às discussões entre si a respeito dos assuntos estudados.

O desejo de criação, livre das amarradas impostas pela sociedade opressora, está presente, também, nos nomes dados aos jovens, os quais são inventados pelos

10 Capitão Fantástico, 2016. 
progenitores na tentativa de fazer com que cada criança seja única: Bodevan, Kielyr, Vespyr, Rellian, Zaja e Nai. Encontra-se perceptível, ainda, uma constante tentativa de expor o conhecimento em seu formato original, sem metáforas ou adaptações etárias, com as crianças sendo educadas a partir de avaliações sociais e encorajadas a desenvolver suas críticas diante de informações diretas. Sem fantasias, que tendem a tornar as referências mais palatáveis e distantes da realidade, os jovens são tratados com uma demonstração de respeito mútuo por suas capacidades intelectuais, emocionais e físicas. Dominando com maestria conteúdos avançados, nas mais diversas áreas de conhecimento, são encorajados a debater temas e elaborar suas próprias ideias, que deveriam ser pautadas em argumentos construídos com rudimentos fundamentados.

O enredo parece apontar para a demonstração de o casal haver realmente granjeado, por meio da criação dos filhos, a vida platônica de reis-filósofos amantes do conhecimento. Todavia, o transcorrer da trama aponta para a situação de que, na verdade, os seis filhos do casal vivam um simulacro do próprio Mito da Caverna ${ }^{11}$, tendo em vista que são incutidos ao saber sem que haja oportunidade de escolhas quanto ao que estudar, ou a que se aprofundar, pois as informações adquiridas são orientadas unicamente pelos pais. Na tentativa de esgueirar-se de um sistema opressor e voltado à irreflexão filosófica, os pais acabam por colocar os filhos, na verdade, em isolamento social e, portanto, alienados às formas de avanços diversos que a humanidade conquistou graças ao uso do conhecimento adquirido no decorrer de sua história.

Em suas pesquisas, Vicente (2014) discute o que é possível esperar da educação de acordo com o modelo idealizado por Platão:

A única solução encontrada por Platão, capaz de resolver essa confusão a respeito da justiça e de muitas outras coisas, é a educação: a experiência da caverna reflete, essencialmente, a natureza humana relativamente à educação ou à sua falta. Sendo assim, essa natureza precisa, necessariamente, de uma educação adequada que possibilite ao homem sair da confusão da caverna e construir uma cidade justa; mas é preciso muito cuidado! Pois, a natureza melhor, sujeita a uma alimentação diversa da que lhe compete, resulte numa coisa pior do que a natureza medíocre. Da mesma forma, as almas mais bem dotadas, se lhes deparar uma educação má, se tornam extremamente perversas. A natureza

11 PLATÃO, 2015. 
desempenha, portanto, um papel importante no processo educativo: a capacidade de um homem para fazer grandes coisas depende dela, pois uma natureza medíocre jamais fará algo de grande a alguém, seja a um particular, seja a uma cidade. (VICENTE, 2014, p. 219-220)

Apreende-se, de acordo com os apontamentos do filósofo referenciado, que a educação faz-se um meio de se alcançar um objetivo (fim), que seria a construção de uma sociedade justa e, por justiça, entende-se cada indivíduo atingindo suas potencialidades dentro de sua pré-determinação. Somente uma instrução eficiente para progredir as aptidões naturais é conveniente para sustentar a justiça na cidade e no indivíduo, sendo tal legitimidade a ocupação por parte de cada um de um encargo equivalente à natureza de suas habilidades e competências (VICENTE, 2014).

A obra Mito da Caverna é uma alegoria criada por Platão, onde se imagina uma situação em que sujeitos se encontram acorrentados e de costas para a entrada, sem poderem ver o meio externo. Assim, sua realidade se resume às sombras que adentram e ficam projetadas às paredes do lugar. Quando um desses sujeitos consegue se libertar, consegue sair, tendo contato direto e real com o mundo exterior e, ao voltar para a caverna, para relatar aos demais suas descobertas, é considerado louco pelos companheiros e assassinado.

A representação metafórica da caverna cabe a situações diversas, com as sombras, a saída, o mundo exterior, por exemplo, oferecendo significados variados. As experiências materiais e sensoriais percebidas, bem como o prisioneiro que se liberta e sai da escuridão, comumente são atribuídas ao papel do filósofo, que busca avaliar a verdade iluminada e, ainda, retirar os demais do obscurantismo, por meio da dialética. Ainda que seja zombado e perseguido, defende que o mundo projetado nas paredes não é o verdadeiro, mas, sim, uma ilusão imposta por governantes como modo de dominação (CHAUÍ, 1999). As metáforas criadas explicam a condição da ignorância e os meios por vezes árduos que precisam de ser percorridos para que se alcance o conhecimento e a aproximação com o chamado mundo real, sem interferência das perspectivas narcisistas e limitadas que sustentam os indivíduos.

Em Capitão Fantástico, a trama coloca a família a questionar e tecer críticas contundentes aos modelos capitalistas de consumo, chegando a denunciar que a forma de as pessoas se relacionarem está pautada em exploração mercadológica, num consumo 
desenfreado e acrítico. Todavia, ao tentarem fugir das ideologias impostas hegemonicamente, criam um mundo paralelo e regido por outras concepções, as quais também se sustentam em princípios conceituais (THOMPSON, 1990), o que aponta para a função do poder coercitivo da ação social, descrito por Weber (2002, p. 37), a exercer força irresistível sobre os indivíduos.

Ao buscar se esquivar da ação social persuasiva e manipuladora, o casal isolase, bem como aos filhos, do convívio social, a fim de que se tornem cidadãos críticos e bem preparados fisicamente, com uma educação impecável - com um nível que a maioria das escolas não poderia prover. Contudo, Fairclough (2003) elucida que o conhecimento adquirido precisa de assumir uma função social, por meio de sua exposição linguística, a fim de gerar práticas sociais funcionais, com discursos, ações, sujeitos e relações sociais, instrumentos, objetos, tempo e lugar, formas de consciência, valores. Para o sociólogo em questão, a comunicação discursiva, em formato interacional, ao mesmo tempo em que é fruto da constituição social, é, também, o componente que constitui as estruturas sociais (FAIRCLOUGH, 2003).

As relações interacionais são cíclicas e promovedoras de causa e efeito, de razão e consequência, o que será sentido por alguns dos filhos, que se sentem privados do convívio social e, com isso, do uso de seu conhecimento enquanto troca de relações humanas, ainda que se sustentem em opiniões opostas. $\mathrm{O}$ resultado do isolamento social será avaliado de forma reflexiva pelo primogênito, que percebe que, fora dos livros, nada sabe. A valorização do conhecimento teórico por parte dos pais foi tamanha, que não avaliaram que estavam privando os jovens de algo fundamental, proporcionado pela escola enquanto ambiente interacional: o convívio social.

Os apontamentos de Abuquerque (2019) desvelam que a educação formal seja um espaço de formação potencial do sujeito coletivo, com perspectiva à emancipação humana. Para a educadora, uma escola não pode se pautar em adestramento produtivo e alienado, orientada por interesses da classe dominante, mas, antes, reivindicar "o acesso ao conhecimento historicamente produzido pela humanidade e a formação da consciência histórica dos sujeitos" (ALBUQUERQUE, 2019, p. 120-121). Importa destacar que, a princípio, a intenção de Bem e Leslie ao idealizar sua família tenha sido a mesma que embasa os educadores quando arquitetam seu papel junto ao ambiente escolar, afinal, buscam, "por meio da educação, possibilidades de desnaturalização dos processos 
sociais" (ALBUQUERQUE, 2019, p. 121), tendo em vista uma formação alçada à percepção consciente do estudante, "ao desenvolvimento social, à elevação cultural, ao desenvolvimento histórico vinculado" à atividade transformadora (ALBUQUERQUE, 2019, p. 121).

Conforme aclara Orlandi (2007), "podemos criar, pela educação, condições para evitar que os sujeitos sejam presos de evidências que os impediriam de colocar-se de modo crítico a realidade que desrespeita a vida, a liberdade, a segurança, o direito ao trabalho, etc" (ORLANDI, 2007, p. 307). Diante dessa reflexão com pretensões práticas, identifica-se que os pais de Capitão Fantástico foram guiados por grandes teóricos e buscaram prover um ensino erudito e elevado aos filhos, todavia, deixando à parte o que é fomentado pela escola, ou seja, um espaço de socialização e a oportunidade de discussão com diferentes, com plurais, numa perspectiva de crescimento mental e emocional. $\mathrm{O}$ contato fora do círculo familiar é importante para que se constitua a própria subjetividade na mediação das relações sociais (ROSETTO; BRABO, 2011), sem as quais não se terá acesso a outros sujeitos que tenham histórias de vida diversas, favorecendo a uma tendência de fechamento insular e alienado, em que informações absorvidas podem se tornar, enfim, acessórios dispensáveis, inúteis e até sem propósito.

Os estudos de Silva e Castro Netto (2018) elucidam que uma educação escolar adequada é um direito por lei e se encontra "diretamente vinculada à inserção dos sujeitos na sociedade. O lugar que esses sujeitos ocupam na sociedade desvela a sua consciência acerca das (des)igualdades, o seu engajamento, a sua ideologia, a sua memória, a sua história, as suas falhas..." (SILVA; CASTRO NETTO, 2018, p. 130). Por isso, vetar os filhos dessa prática social termina por, infelizmente, induzi-los a alheamentos e desafeições diversas, que seriam imprescindíveis para a formação humana de seus caráteres. A prática da família de Capitão Fantástico, então, construiu jovens fortes e altamente eruditos, todavia, fracos e ignorantes em relações intersociais - que é uma das importantes marcas da construção histórica do ser humano e, igualmente, o que o tornou o animal a dominar os demais. 


\section{Considerações finais}

A ideia de trazer este filme para discutirmos a relação da escola com a educação foi pensada justamente por se tratar de um modelo que visa a fugir do poder coercitivo da ação social. Em seu desfecho, porém, a família entende que, na verdade, o que fazia promovia uma castração social que acarretaria em depressões emocionais, as quais impediriam o desenvolvimento pleno das faculdades de composição dos jovens. Ao encerrar os filhos à uma realidade que acreditavam ser perfeita, Bem e Leslie não lhes ofereciam possibilidade de escolha ou condição de enfretamento de ideias, por nãos lhes permitir conhecerem outras práticas e pensamentos.

Com essa narrativa cinematográfica, é possível avaliar a importância das ciências sociais - como sociologia e filosofia - como base de teorização e formação de pensamento fortalecido e, da mesma forma, seu uso na defesa de direitos e na sustentação da igualdade social. Tecnologia persuasiva, inibidora de pensamento reflexivo e contestador, é uma forma agressiva de impedir o desenvolvimento humano, afinal, é das ciências sociais que vêm a ponderação a respeito da ética, que se originam as reflexões humanas e, ainda, que se impulsionam as buscas tecnológicas. $\mathrm{O}$ apego ao conhecimento, às descobertas, à verdade e aos valores morais se originam das faculdades humanas, que promovem reflexões que vêm a se tornar comportamentos sociais de busca por direitos: do homossexual, da mulher, do não cristão, do pobre.

Importa considerar que o Brasil presencia um momento de crise das concepções de educação, de disciplina, de direito legal e, ainda, de respeito ao diferente. A retomada de modelos conservadores e a forma como se lida com conquistas já feitas, tentando derrubá-las, rompe com modelos de concepção da realidade, ainda que imersos em fatos sociais, e desnuda a capacidade humana de transformação transgressora e retrógrada. Não é o bastante a conformação a paradigmas dados sem a constante luta por condições dignas de educação, ou, ainda, a imposição de sistemas tecnológicos como maquiagem de crescimento educacional, quando professores e alunos estão em escolas precárias e têm sua individualidade desrespeitada por ideologias hostis e intolerantes.

O desfecho do filme Capitão Fantástico consiste na família encontrar um meio termo entre os radicalismos do total isolamento com a reprodução de modos de 
consumo e relacionamentos acríticos, e a família passa a viver em uma casa suficiente para todos, com as crianças frequentando a escola em busca de crescimento emocional e relacional. Tal desenlace da trama pode ser tomado como uma conclamação, apontando que é possível, sim, aprofundar-se na erudição e a utilizar como recurso de poder para resistir, arrostar e esclarecer, afinal, há os que desejam sair da caverna. Lidar com as crises é buscar soluções e reinventar existências, é adaptar-se à realidade sem deixar questionamentos e buscar por soluções que incluem.

Portanto, ao invés de se fugir da realidade opressora para se criar reisfilósofos, que tais sejam formados nas escolas, nas casas, nas ruas, nas igrejas. Que a filosofia e a sociologia permaneçam como criadoras de pensadores grandiosos, de ideais humanitários e de uma educação libertadora (FREIRE, 2013). Que esses reis cresçam, multipliquem-se, espalhem-se e, ao invés de se isolarem do mundo, reconstruam-no aos moldes clássicos, ao formato erudito, às forças de crescimento ético, às bases do respeito humano e se tornem patronos de pensamentos libertadores.

\section{REFERÊNCIAS}

ALBUQUERQUE, L. C. R. de. Emancipação humana e emancipação política: limites e possibilidades das políticas educacionais na sociabilidade capitalista. In: KUNZ, S. A. da S. [et al] (org.) Direitos humanos e emancipação, v.1 [Coleção Direitos Humanos]. Uberlândia: Culturatrix, 2019, p. 105-125.

CAPITÃO FANTÁSTICO. Matthew Brandon Ross. Estados Unidos: Universal, (s.d.). 1 DVD (120 min), 2016.

CAPRA, F. Crise e Transformação. In: CAPRA, F. O ponto de mutação: a ciência, a sociedade e a cultura emergente. São Paulo: Cultrix, 2006. p. 11-39.

CHAUÍ, M. Convite à filosofia. São Paulo: Ed. Ática, p. 40-41, 1999.

CONSELHO NACIONAL DOS DIREITOS HUMANOS. Nota de Apoio à resolução n $^{0} 01 / 99$ do conselho federal de psicologia. Brasília, 2017. 
DESCARTES, R. Discurso do método; Princípios da filosofia. São Paulo: Folha de S. Paulo, 2010.

DURKHEIM, É. Educação e sociologia. Petrópolis/RJ: Vozes, 2011.

EXAME terá aplicação digital em fase piloto em 2020 e deixará de ter versão em papel em 2026. 03 jul. 2019. Disponível em: http://portal.inep.gov.br/artigo/-

/asset_publisher/B4AQV9zFY7Bv/content/exame-tera-aplicacao-digital-em-fase-pilotoem-2020-e-deixara-de-ter-versao-em-papel-em-2026/21206. Acesso em 20 jan. 2020.

FAIRCLOUGH, N. Analyzing discourse: Textual analysis for social research. London, New York: Routledge, 2003.

FREIRE, P. Pedagogia do oprimido. Rio de Janeiro: Paz e Terra, 2013.

KRESS, G; VAN LEEUWENT, T. Muldimodal discourse: the grammar of visual design. London and New York: Routledge, 2. ed. 2006.

LA BOÉTIE, E. Discurso sobre a servidão voluntária. Brasília: LGE Editora, 2009.

LOPES, V. F. O poder da renúncia sublimado no discurso: análise crítica de correspondências históricas. Tese de Doutorado inédita, 279 pp. Brasília: Universidade de Brasília, 2019.

LOPES, V. F; SILVA, D. E. G. da. Discurso e pobreza na ausência de escolhas: a voz feminina de identidades perdidas. In: SILVA, D. E. G. da. (org.) Práticas semióticodiscursivas - texto e imagem na (re)construção de identidade. Brasília: Thesaurus, 2019. p. 89-114.

NUNES, P. A. M. Como se computa a violência homofóbica no Brasil? Dados, reconhecimento e visibilidade do movimento LGBT em Maceió-AL. (Dissertação de Mestrado em Sociologia). Universidade Federal de Alagoas - Maceió, 2018.

ORLANDI, E. P. Educação em Direitos Humanos: um discurso. In: SILVEIRA, R. M. 
G [et al]. Educação em Direitos Humanos: fundamentos teórico-metodolóicos. João Pessoa: Editora Universitária, 2007.

PAVIANI, J. Filosofia e método em Platão. Porto Alegre: EDIPUCRS, 2001.

PLATÃO. A República. Fortaleza: Edições UFC, 2009.

PLATÃO. O mito da caverna. São Paulo: Edipro, 2015.

POSTER, M. A segunda era dos media. Tradução Maria J. Taborda e Alexandra Figueiredo. The Second Media Age. Celta: Oeiras, 2000.

POPULAÇÃO brasileira tem alto grau de conservadorismo, aponta IBOPE. 22 dez. 2016. Disponível em: https://noticias.r7.com/brasil/populacao-brasileira-tem-alto-graude-conservadorismo-aponta-ibope-22122016. Acesso em 20 jan. 2020.

RONAN, C. A. História ilustrada da ciência. Universidade de Cambridge III - Da Renascença à Revolução científica. São Paulo: Círculo do Livro, 1987.

SILVA, G. B. da; CASTRO NETTO, M. I. de. (re)significados dos direitos humanos da criança e do adolescente sob a ótica da discursividade. In: SILVA, A. A. da; KUNZ, S. A. da S. (org.). Direitos humanos e educação. Uberlândia: Culturatrix, 2018.

THOMPSON, J. B. Ideologia e cultura moderna: teoria social crítica na era dos meios de comunicação de massa. Petrópolis, RJ: Vozes, 1990.

VICENTE, J. J. N. B. O papel da educação na república de Platão. Kínesis, Vol. VI, $\mathrm{n}^{\circ} 11$, p. 215-224, Julho 2014.

VIEIRA, J. A.; SILVESTRE, C. Introdução à Multimodalidade: Contribuições da Gramática Sistêmico-funcional, Análise de Discurso Crítica e Semiótica Social. Brasília: Cepadic, 2015.

WEBER, M. Conceitos Básicos de Sociologia. São Paulo: Centauro, 2002. 
https://twitter.com/jairbolsonaro/status/1121713997156425729. Acesso em 26 de abr. 2019.

Recebido em: 15/112021

Aprovado em: 10/12/2021

Publicado em: 15/12/2021 